\title{
TEOR DE PROTEÍNA NO METABOLISMO DO NITROGÊNIO E DA ENERGIA EM SUÍNOS DURANTE O CRESCIMENTO
}

\author{
Low crude protein diets on the nitrogen and energy metabolism of growing pig
}

\author{
Vladimir de Oliveira', Elias Tadeu Fialho², José Augusto Freitas Lima ${ }^{3}$, Antônio Gilberto Bertechini \\ Rilke Tadeu Fonseca de Freitas ${ }^{3}$
}

\begin{abstract}
RESUMO
O experimento foi realizado no DZO/UFLA com o objetivo de avaliar os efeitos do teor de proteína bruta no metabolismo do nitrogênio e energia em suínos durante o crescimento. Foram utilizados 12 suínos machos castrados, alojados individualmente em gaiolas de estudo de metabolismo e os tratamentos utilizados consistiram de rações isoenergéticas e isolisínicas, formuladas segundo o conceito de proteína ideal, para atender os teores de proteína bruta 16,14, 12 e $10 \%$. A quantidade de ração fornecida foi 3,5 vezes a energia de manutenção, calculada como $106 \mathrm{kcal}$ de $\mathrm{EM} / \mathrm{kgPV}^{0,75}$ e ajustada diariamente de acordo com o ganho de peso esperado. $\mathrm{O}$ experimento foi realizado em dois períodos consecutivos de 12 dias . Os sete primeiros dias foram utilizados para adaptação dos animais e os cinco dias restantes para coleta total de fezes e urina. O delineamento experimental foi o changeover balanceado em dois períodos. Com a redução do teor de proteína bruta, o nitrogênio excretado diminui linearmente $(\mathrm{P}<0,01)$. Verificou-se que a cada ponto percentual de redução no teor de proteína da ração, 10,8\% menos nitrogênio é eliminado na urina. Houve redução linear $(\mathrm{P}<0,01)$ na retenção de nitrogênio com o decréscimo de proteína da ração. A eficiência de utilização do nitrogênio consumido aumentou proporcionalmente com a redução do conteúdo de proteína. Os coeficientes de metabolização das rações foram semelhantes $(\mathrm{P}>0,05)$, mas a relação entre energia metabolizável e digestível foi inversamente proporcional à concentração de proteína das rações experimentais. Conclui-se que a redução do teor de proteína diminui a retenção de nitrogênio, mas reduz a excreção e aumenta a eficiência de utilização do nitrogênio ingerido.
\end{abstract}

Termos para indexação: Nutrição e dejetos, balanço de nitrogênio, suinocultura.

\begin{abstract}
An experiment was conducted in the department of Animal Science at the Universidade Federal de Lavras (Federal University of Lavras) for evaluate the effects of protein levels in the nitrogen and energy balance. Twenty crossbred barrows were housed individually metabolism cages and distributed in four treatments. Treatments were isoenergetics and isolisinics diets formulated according ideal ratio of amino acids, but with different crude protein levels $(16,14,12$ and $10 \%)$. The pigs were fed three times energy required for maintenance, which was assumed to be $106 \mathrm{kcal}$ of ME/kg of metabolic body weight ${ }^{0.75}$. The rations were adjusted each day on the basis of an estimated weight gain. The experiment was conducted in two consecutive periods of 12 days each. Seven first days were used for adaptation of animals and the five last days was used total of feces and urine collection. Ferric oxide was used as a marker. The experimental design was balanced changeover in two periods. The decrease of crude protein levels resulted in linearly reduction $(\mathrm{P}<0.001)$ of total nitrogen excretion. For each percent reduction in dietary $\mathrm{CP}$, urine nitrogen excretion was reduced about $10.8 \%$. Nitrogen retention was decreased linearly $(\mathrm{P}>0.01)$ for those pigs fed diets with reduced protein. However, nitrogen efficiency utilization of intake nitrogen increased proportionally with decreased crude protein levels. The metabolization coefficients of energy diets showed similarity $(\mathrm{P}>0.05)$ values, but metabolizable :digestible energy ratio were inversely proportionally to the crude protein levels. In conclusion, the reduction of crude levels protein of rations decrease nitrogen retention, although result less nitrogen excretion and increase efficiency utilization of nitrogen intake.
\end{abstract}

Index terms: Slurry and nutrition, nitrogen balance, pig production.

(Recebido para publicação em 9 de junho de 2004 e aprovado em 4 de maio de 2005)

\section{INTRODUÇÃO}

Os suínos excretam nas fezes e urina parcelas significativas do nitrogênio ingerido, e a poluição causada pelo nitrogênio é um problema grave em regiões onde a densidade populacional desses animais é elevada.

É possível reduzir as perdas de nitrogênio diminuindo-se o teor de proteína bruta das rações, desde que se faça adição de aminoácidos sintéticos para evitar deficiências de aminoácidos essenciais. Essa hipótese foi confirmada por vários autores, contudo, na maior parte desses estudos o teor mínimo de proteína usado esteve próximo a 14\%, teor abaixo do qual uma ração com milho e farelo de soja destinada a suínos em fase de crescimento tem, além de outros

\footnotetext{
1 Zootecnista, DSc., Professor do Centro de Ciências Agrárias - UNIOESTE - Caixa Postal 1008 - 85960000 - Mal. Cândido Rondon, PR v.oliveira@brturbo.com

${ }^{2}$ Engenheiro Agrônomo, Ph D., Professor do Departamento de Zootecnia - Universidade Federal de Lavras/UFLA - Caixa Postal 3037 - $37.200-000$ Lavras, MG.

${ }^{3}$ Zootecnista, DSc. Professor do Departamento de Zootecnia/UFLA.
} 
aminoácidos limitantes como lisina, treonina, metionina e triptofano.

Em estudos nos quais a redução protéica foi mais acentuada, verificou-se a mesma tendência de queda na excreção de nitrogênio, mas os resultados foram divergentes na variável retenção de nitrogênio. Em alguns experimentos não houve redução do nitrogênio retido (LE BELLEGO et al., 2001); em outros a retenção foi inferior nas rações menos protéicas, mesmo quando ajustadas para atender as exigências de aminoácidos (KEPARTT \& SHERRITT, 1990; KERR \& EASTER, 1995). Existem poucos trabalhos abordando esta questão com suínos na fase de crescimento. Considerando-se a importância de reduzir o teor de proteína bruta de rações, um experimento foi realizado com o objetivo de quantificar a influência do teor de proteína bruta no balanço de nitrogênio e energia de suínos em crescimento.

\section{MATERIALEMÉTODOS}

O experimento foi conduzido na sala de estudo de metabolismo do setor de suinocultura do DZO/UFLA, utilizando-se 12 suínos machos castrados $(36,33 \pm 0,80 \mathrm{~kg})$ com alto potencial para deposição de carne magra. Os suínos foram alojados individualmente em gaiolas de metabolismo, semelhantes as descritas por Pekas (1968). O experimento foi realizado em dois períodos consecutivos com duração de 12 dias cada, nos quais os sete primeiros dias foram destinados à adaptação dos animais às dietas experimentais, enquanto os cinco dias restantes utilizados para colheita total de fezes e urina. O óxido férrico foi usado como marcador fecal. As fezes foram colhidas diariamente, acondicionadas em sacos plásticos e armazenadas em freezer $\left(-20^{\circ} \mathrm{C}\right)$. Ao final do período experimental, as fezes foram homogeneizadas e retirou-se uma alíquota para análises químicas. A urina foi colhida em baldes plásticos que continham $20 \mathrm{ml}$ de $\mathrm{HCl}(6 \mathrm{~N})$ para evitar contaminação bacteriana e perdas de nitrogênio. Diariamente, o volume total de urina de cada animal foi filtrado, quantificado, homogeneizado e retirou-se uma alíquota $(10 \%)$ que foi armazenada em refrigerador $(1 \mathrm{C})$. No final do período de colheita, retirou-se do volume total de urina uma amostra que foi imediatamente encaminhada ao laboratório de produção animal (LPA/DZO/UFLA) para determinação do nitrogênio.

Os tratamentos experimentais foram quatro rações isoenergéticas e isolisínicas que variaram no teor de proteína bruta (Tabela 1). As rações foram formuladas para manter a relação ideal entre aminoácidos proposta por Baker (1994). As rações foram formuladas usando a mesma partida de milho e farelo de soja e misturadas em batidas de $50 \mathrm{~kg}$ visando garantir a homogeneidade. Houve suplementação dos aminoácidos sintéticos: L-lisina, L-treonina, DL-metionina, L-triptofano, L-leucina, Lfenilalanina e L-histidina. A digestibilidade dos aminoácidos sintéticos foi considerada $100 \%$. A quantidade de lisina digestível verdadeira foi calculada para atender no mínimo 0,83\% da ração (NRC, 1998). A relação entre nitrogênio essencial e não-essencial (NE:NT) foi calculada conforme Heger et al. (1998). Os valores de energia líquida foram calculados a partir da composição de análise química das rações experimentais, de acordo com a equação sugerida por Noblet et al. (1994). Todas as rações foram suplementadas com vitaminas e minerais.

Os animais foram pesados no início do período de adaptação e no início e final do período de colheita. A quantidade de ração fornecida foi de 3,5 vezes a energia de manutenção, calculada como $106 \mathrm{kcal}$ de EM/kg PV ${ }^{0,75}$ (NRC, 1998). No período de adaptação, a quantidade de ração fornecida foi ajustada diariamente de acordo com o ganho de peso esperado. No período de colheita, a quantidade de ração fornecida foi calculada com base no peso obtido no primeiro dia de colheita e mantida constante até o final do período. A ração foi umedecida com água na proporção de 2:1 (água:ração). Após o consumo de ração, todos os suínos receberam água à vontade.

A matéria seca dos ingredientes, rações e fezes foi determinada em estufa com ar forçado $\left(60^{\circ} \mathrm{C}\right)$ até atingir peso constante e, posteriormente em estufa $\left(105^{\circ} \mathrm{C}\right)$ por 24 horas. $\mathrm{O}$ nitrogênio dos ingredientes, rações, fezes e urina foi determinada usando o método de Kjeldahl (AOAC, 1990). Uma bomba calorimétrica adiabática foi utilizada para determinar a energia bruta dos ingredientes, rações, fezes e urina. A fibra em detergente ácido (FDA) e a fibra em detergente neutro (FDN) foram analisadas usando Soest \& Wine (1967). O extrato etéreo, cinzas e amido foram determinados conforme metodologias descritas por Silva \& Queiroz (2002).

O experimento foi realizado usando um delineamento changeover balanceado em dois períodos e com quatro tratamentos, conforme Gill \& Magee (1976). As análises estatísticas dos dados foram realizadas usando o PROC GLM do SAS®. Os efeitos do tratamento, animal e período experimental foram decompostos e analisados de acordo com o seguinte modelo experimental: $\mathrm{Y}_{\mathrm{ijk}}=\mu+\mathrm{T}_{\mathrm{i}}+\mathrm{A}_{\mathrm{j}}+\mathrm{P}_{\mathrm{k}}$ $+\mathrm{e}_{\mathrm{ijk}}$, em que: $\mathrm{Y}_{\mathrm{ijk}}$ é a variável dependente, $\mu$ é a média geral, $T_{i}$ é o efeito de tratamento (i $=1,23$ e 4$), A_{j}$ é o efeito do animal $(\mathrm{j}=1,2, \ldots ., 12), P_{k}$ é o efeito do Período $(\mathrm{k}=1,2) \mathrm{e}$ 
TABELA 1 - Composição das rações experimentais.

\begin{tabular}{|c|c|c|c|c|}
\hline \multirow{2}{*}{ Ingrediente (\%) } & \multicolumn{4}{|c|}{ Teor de Proteína Bruta (\%) } \\
\hline & 10 & 12 & 14 & 16 \\
\hline Milho & 54,175 & 75,63 & 84,395 & 78,67 \\
\hline Amido & 34,0 & 11,52 & - & - \\
\hline Farelo Soja & 6,6 & 8,5 & 11,75 & 18,0 \\
\hline Fosfato Bicálcico & 1,50 & 1,50 & 1,50 & 1,50 \\
\hline Calcário & 0,90 & 0,90 & 0,90 & 0,90 \\
\hline Sal & 0,40 & 0,40 & 0,40 & 0,40 \\
\hline Premix Vitamínico & 0,10 & 0,10 & 0,10 & 0,10 \\
\hline Premix Mineral & 0,10 & 0,10 & 0,10 & 0,10 \\
\hline L-lisina $\mathrm{HCl}$ & 0,71 & 0,58 & 0,45 & 0,24 \\
\hline L-treonina & 0,35 & 0,26 & 0,18 & 0,08 \\
\hline L-triptofano & 0,10 & 0,08 & 0,05 & 0,01 \\
\hline DL-metionina & 0,14 & 0,09 & 0,06 & - \\
\hline L-valina & 0,26 & 0,14 & 0,045 & - \\
\hline L-isoleucina & 0,25 & 0,15 & 0,07 & - \\
\hline L-Leucina & 0,14 & - & - & - \\
\hline L-Fenilalanina & 0,19 & 0,05 & - & - \\
\hline L Histidina & 0,085 & - & - & - \\
\hline $\begin{array}{l}{ }^{2} \text { Suplemento vitamínico: Vit. } \\
\text { (1.000 mg), Riboflavina ( } 4.00 \\
\text { fólico }(600 \mathrm{mg}) \text {, Biotina }(50 \mathrm{~m} \\
{ }^{2} \text { Suplemento mineral: Cobre } \\
\text { Ferro }(70.000 \mathrm{mg}) \text {, Cobalto }(50\end{array}$ & $\begin{array}{l}0 \mathrm{mg}) \text {, } \\
\mathrm{o}(800\end{array}$ & $\begin{array}{l}0 \\
\text { UI), V } \\
\text { ina }(25 \\
\text { e }(125 \mathrm{~m} \\
\text { ês }(40.0\end{array}$ & $\begin{array}{l}\mathrm{mg}), \mathrm{V} \\
\text { c. Panto } \\
\text { ico }(15.0 \\
\text { enio }(15\end{array}$ & $\begin{array}{l}\mathrm{mg}) \\
0 \mathrm{mg}) \\
(80.00\end{array}$ \\
\hline
\end{tabular}

$e_{\mathrm{ijk}}$ é o erro experimental associado às observações. No caso de análise de variância significativa para tratamentos, a soma de quadrados foi decomposta em efeitos linear e quadrático usando contrastes ortogonais. Utilizou-se o procedimento CONTRAST do SAS para realização dessa análise. Nesse caso, considerou-se que os teores de proteína foram igualmente espaçados.

\section{RESULTADOS E DISCUSSÃO}

Durante o período experimental, aparentemente , não ocorreram problemas de saúde e os animais consumiram toda a ração fornecida.

Os consumos de lisina digestível verdadeira (LDIV), energia metabolizável (EM) e a relação entre LDIV e EM são apresentados na Tabela 3. Não houve diferenças $(\mathrm{P}>0,05)$ entre os tratamentos para essas variáveis e isso está de acordo com os objetivos estabelecidos para o experimento.

Os resultados do balanço de nitrogênio, expressos em g/d e g/kgPV ${ }^{0,75} /$ dia, são apresentados na Tabela 4.

A redução do teor de proteína bruta resultou em menor consumo e excreção de nitrogênio $(\mathrm{P}<0,001)$, independente da unidade em que os dados foram calculados. A quantidade de nitrogênio das fezes decresceu linearmente $(\mathrm{P}>0,001)$ com a redução do teor de proteína da ração. Esses resultados são semelhantes aos obtidos por Figueroa et al. (2002) e Le Bellego et al. (2001), que também verificaram aumento no nitrogênio fecal com o incremento de proteína na ração. A variação no nitrogênio fecal está relacionada com a quantidade de nitrogênio ingerido. $\mathrm{O}$ nitrogênio eliminado na urina

Ciênc. agrotec., Lavras, v. 29, n. 4, p. 866-874, jul./ago., 2005 
TABELA 2 - Composição química das rações experimentais.

\begin{tabular}{|c|c|c|c|c|c|c|c|c|}
\hline \multirow[b]{2}{*}{ Composição } & \multicolumn{8}{|c|}{ Teor de Proteína Bruta (\%) } \\
\hline & \multicolumn{2}{|c|}{10} & \multicolumn{2}{|c|}{12} & \multicolumn{2}{|c|}{14} & \multicolumn{2}{|c|}{16} \\
\hline $\mathrm{EM}(\mathrm{Kcal} / \mathrm{kg})$ & \multicolumn{2}{|c|}{3292} & \multicolumn{2}{|c|}{3291} & \multicolumn{2}{|c|}{3290} & \multicolumn{2}{|c|}{3300} \\
\hline PB (\%) & \multicolumn{2}{|c|}{9,73} & \multicolumn{2}{|c|}{12,26} & \multicolumn{2}{|c|}{14,30} & \multicolumn{2}{|c|}{16,22} \\
\hline Fósforo Disp. (\%) & \multicolumn{2}{|c|}{0,310} & \multicolumn{2}{|c|}{0,321} & \multicolumn{2}{|c|}{0,330} & \multicolumn{2}{|c|}{0,338} \\
\hline Cálcio & \multicolumn{2}{|c|}{0,740} & \multicolumn{2}{|c|}{0,746} & \multicolumn{2}{|c|}{0,758} & \multicolumn{2}{|c|}{0,779} \\
\hline Lisina $(100)^{1}$ & 0,846 & $(100)^{2}$ & 0,831 & $(100)$ & 0,837 & $(100)$ & 0,833 & (100) \\
\hline Treonina (65) & 0,553 & (65) & 0,553 & (66) & 0,554 & (66) & 0,549 & (66) \\
\hline Triptofano (18) & 0,159 & (19) & 0,162 & (19) & 0,157 & (19) & 0,153 & (18) \\
\hline Metionina (30) & 0,258 & (30) & 0,253 & (30) & 0,256 & (31) & 0,255 & (30) \\
\hline Met + Cist (60) & 0,392 & (46) & 0,436 & (52) & 0,475 & (57) & 0,504 & (60) \\
\hline Valina (68) & 0,573 & (68) & 0,565 & (68) & 0,565 & (67) & 0,626 & (75) \\
\hline Isoleucina (60) & 0,504 & (59) & 0,493 & (59) & 0,497 & (59) & 0,534 & (64) \\
\hline Fenilalanina (50) & 0,518 & (61) & 0,495 & (59) & 0,546 & (65) & 0,659 & (79) \\
\hline Fenil + Tir (95) & 0,747 & (88) & 0,803 & (96) & 0,926 & (111) & 1,129 & (135) \\
\hline Histidina (32) & 0,269 & (32) & 0,250 & (30) & 0,305 & (36) & 0,366 & (44) \\
\hline Leucina (100) & 0,846 & (100) & 0,964 & (116) & 1,150 & (137) & 1,301 & (156) \\
\hline Arginina (42) & 0,395 & (47) & 0,528 & (63) & 0,663 & (79) & 0,848 & (102) \\
\hline NE:NT Digestível & \multicolumn{2}{|c|}{0,48} & \multicolumn{2}{|c|}{0,39} & \multicolumn{2}{|l|}{0,33} & \multicolumn{2}{|l|}{0,30} \\
\hline NE:NT & \multicolumn{2}{|c|}{0,44} & \multicolumn{2}{|c|}{0,36} & \multicolumn{2}{|l|}{0,31} & \multicolumn{2}{|l|}{0,27} \\
\hline $\mathrm{BE}(\mathrm{Na}+\mathrm{K}-\mathrm{Cl})^{3}$ & \multicolumn{2}{|c|}{41} & \multicolumn{2}{|c|}{75} & \multicolumn{2}{|l|}{107} & \multicolumn{2}{|l|}{148} \\
\hline
\end{tabular}

${ }^{1}$ Relação entre lisina e demais aminoácidos sugerida por Baker (1994).

${ }^{2}$ Relação entre lisina e demais aminoácidos do presente experimento (conforme NRC, 1998).

${ }^{3}$ Expresso em miliequivalente por grama (meq/grama).

diminuiu linearmente $(\mathrm{P}<0,001)$ em razão da menor ingestão de nitrogênio ( Figura 1). Verificou-se redução de, aproximadamente , $11 \%$ no nitrogênio urinário a cada ponto percentual de decréscimo no conteúdo de proteína da ração. Canh et al. (1998) e Kerr \& Easter (1995), também encontraram valores próximos a $11 \%$. Houve significativa redução de nitrogênio eliminado na urina, o que é perfeitamente justificável, pois a urina é a principal via de eliminação do nitrogênio em excesso no organismo dos suínos.

A digestibilidade aparente do nitrogênio foi semelhante $(\mathrm{P}>0,05)$ entre os tratamentos estudados. Fan et al. (1994) e Li et al. (1994), ao contrário, observaram menor digestibilidade do nitrogênio em razão do aumento na proporção de nitrogênio metabólico nas fezes, que ocorre com o decréscimo de proteína da ração. A proporção de nitrogênio metabólico não específico foi estimado em $48 \%$ e $22 \%$, para rações com 9,85 e 14,64\% de proteína, respectivamente (OTTO et al., 2003). Dessa forma, o decréscimo da digestibilidade aparente do nitrogênio parece estar mais relacionado com limitações da técnica de balanço, do que com os tratamentos experimentais. 
TABELA 3 - Consumo de lisina, energia metabolizável (EM) e a relação entre lisina:EM ingerida.

\begin{tabular}{|c|c|c|c|c|c|}
\hline \multirow{2}{*}{ Variável } & \multicolumn{4}{|c|}{ Teor de PB (\%) } & \multirow{2}{*}{ EPM } \\
\hline & 10 & 12 & 14 & 16 & \\
\hline Consumo Lisina ${ }^{1}$ & 0,91 & 0,90 & 0,89 & 0,89 & 0,002 \\
\hline Consumo $\mathrm{EM}^{2}$ & 351,3 & 349,9 & 352,7 & 350,4 & 1,477 \\
\hline Lisina: $\mathrm{EM}^{3}$ & 2,58 & 2,58 & 2,59 & 2,57 & 0,023 \\
\hline
\end{tabular}

TABELA 4 - Efeito do teor de proteína bruta no balanço de nitrogênio de suínos em crescimento.

\begin{tabular}{|c|c|c|c|c|c|}
\hline \multirow[t]{2}{*}{ Variável } & \multicolumn{4}{|c|}{ Teor de PB (\%) } & \multirow{2}{*}{ EPM } \\
\hline & 10 & 12 & 14 & 16 & \\
\hline Nitrogênio Ingerido(g/dia)* & 31,05 & 38,76 & 45,83 & 52,64 & 0,398 \\
\hline Nitrogênio Ingerido(g/kg PV $\left.{ }^{0,75} / \mathrm{dia}\right)^{*}$ & 1,68 & 2,08 & 2,44 & 2,78 & 0,005 \\
\hline Nitrogênio Fezes $(\mathrm{g} / \mathrm{dia})^{*}$ & 3,84 & 4,78 & 6,16 & 6,27 & 0,201 \\
\hline Nitrogênio Fezes (g/kg PV $00,75 /$ dia)* & 0,21 & 0,26 & 0,33 & 0,33 & 0,012 \\
\hline Nitrogênio Urina $(\mathrm{g} / \mathrm{dia})^{*}$ & 4,46 & 8,65 & 11,83 & 16,64 & 0,323 \\
\hline Nitrogênio Urina $\left(\mathrm{g} / \mathrm{kg} \mathrm{PV} \mathrm{PV}^{0,75} / \mathrm{dia}\right)^{*}$ & 0,24 & 0,46 & 0,63 & 0,88 & 0,015 \\
\hline Excreção Total N (g/dia)* & 8,31 & 13,44 & 17,99 & 22,91 & 0,233 \\
\hline Excreção Total N (g/kg PV $\left.{ }^{0,75} / \mathrm{dia}\right)^{*}$ & 0,45 & 0,72 & 0,96 & 1,21 & 0,017 \\
\hline Nitrogênio Retido (g/dia)* & 22,74 & 25,32 & 27,84 & 29,72 & 0,388 \\
\hline Nitrogênio Retido (g/kg PV $\left.{ }^{0,75} / \mathrm{dia}\right)^{*}$ & 1,24 & 1,36 & 1,49 & 1,57 & 0,015 \\
\hline Eficiência de Utilização Nitrogênio (\%)* & 73,5 & 65,5 & 60,8 & 56,5 & 0,723 \\
\hline Digestibilidade N (\%) & 87,2 & 87,7 & 86,6 & 87,9 & 0,393 \\
\hline
\end{tabular}

* Regressão linear significativa $(\mathrm{P}<0,001)$.

$\mathrm{EPM}=$ Erro padrão da média.

Ciênc. agrotec., Lavras, v. 29, n. 4, p. 866-874, jul./ago., 2005 


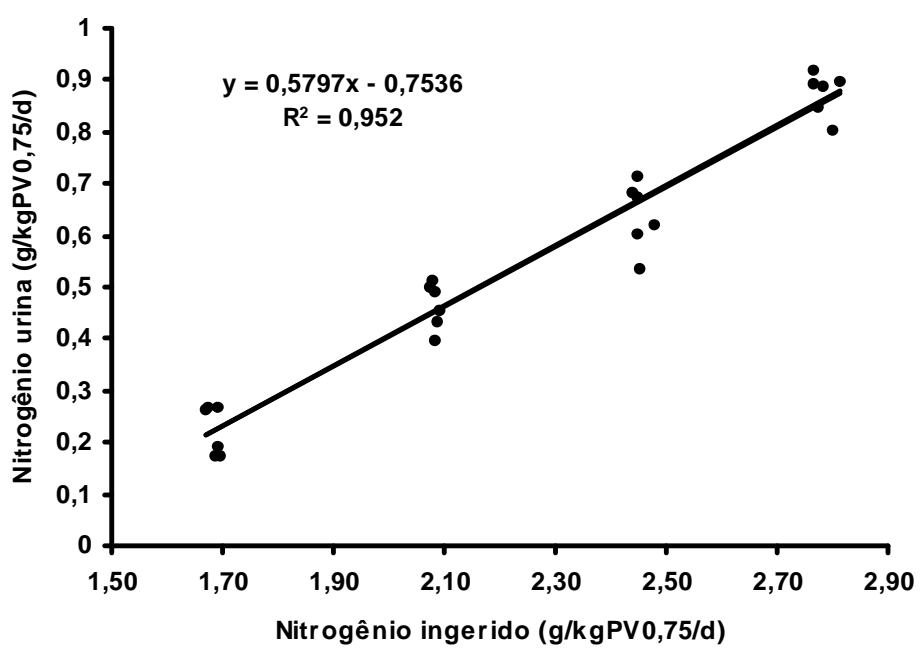

FIGURA 1 - Relação entre o nitrogênio ingerido e o nitrogênio eliminado na urina.

A retenção de nitrogênio diminuiu linearmente $(\mathrm{P}<0,01)$ com a redução do teor de proteína das rações ( Figura 2). É possível que outros fatores tenham limitado a retenção de nitrogênio, como por exemplo, a relação entre nitrogênio essencial e nitrogênio total (NE:NT) das rações. Para ocorrer a síntese de proteínas deve haver disponibilidade tanto de aminoácidos essenciais como de aminoácidos não-essenciais, ou seja, no meio celular todos os aminoácidos são considerados essenciais (BEDFORD \& SUMMERS, 1985).

Alguns autores realizaram experimentos para estimar a relação ótima entre NE:NT para suínos. Visando a máxima retenção de nitrogênio, os valores estimados por Heger et al. (1998), Lenis et al. (1999) e Wang \& Fuller (1989), foram de $0,42,0,48$ e 0,50 , respectivamente. Relações superiores a estas causam menor retenção de nitrogênio, pois aminoácidos essenciais são usados para síntese de aminoácidos não-essenciais. A relação entre NE:NT das rações experimentais está na Tabela 2. Verificou-se que a ração com $10 \%$ de proteína bruta apresenta relação NE:NT superior à encontrada por Wang \& Fuller (1989), 0,44 versus 0,42, mas inferior as outras estimativas. Apesar das explicações anteriores serem aceitáveis para a ração $10 \%$ de $\mathrm{PB}$, não se aplicam as rações $12 \%$ e $14 \%$ de $\mathrm{PB}$, que apresentaram relação NE:NT superior a ótima (Tabela 2) e o consumo de nitrogênio diário foi acima de dois gramas por quilo de peso metabólico.

Em estudo conduzido por Le Bellego et al. (2001), foi registrado redução de $12 \%$ na retenção de nitrogênio quando rações com 18,9 e 12,3\% de proteína bruta foram comparadas. Mesmo que essa diferença não tenha sido detectada na análise estatística, é importante considerar que a ração com 12,3\% de proteína usada por Le Bellego et al. (2001), e as rações com 14\% e 12\% de PB, usadas no presente experimento, continham L-valina e L-isoleucina ( aminoácidos sintéticos que ainda não estão disponíveis para uso industrial). Assim, é possível que as relações dos aminoácidos valina e isoleucina com a lisina, sugerida por Baker (1994) e usadas no presente experimento, subestimem as exigências desses aminoácidos.

A eficiência de rações suplementadas com grandes quantidades de aminoácidos sintéticos é controversa. Devido à significativa redução do teor protéico da ração, a disponibilidade de aminoácidos na forma de di e tripeptídeos pode ter reduzido. Em humanos adultos, aproximadamente $33 \%$ da proteína é absorvida como aminoácidos e o restante (67\%) como peptídeos (ZALOGA, 1990). Peptídeos são utilizados como fontes preferenciais para síntese de proteína. Assim, a redução da proteína da dieta pode limitar a disponibilidade de peptídeos para síntese de proteínas musculares. Estudos conduzidos em cobaias evidenciam que rações baseadas em aminoácidos resultaram em atrofia intestinal e permeabilidade do intestino (BIRKE et al., 1990), além de reduzir a retenção de nitrogênio e o crescimento dos animais (POULLAIN et al., 1989).

Heger et al. (1998) enfatizam que a maior retenção 
de nitrogênio observada em experimentos de curta duração pode ocorrer devido à respostas adaptativas ao consumo excessivo de nitrogênio não essencial.

A eficiência de utilização do nitrogênio foi reduzida linearmente $(\mathrm{P}<0,01)$ com o aumento do teor de proteína bruta das rações (Figura 3). Estes resultados foram observados por Heger et al. (1998). É possível que ocorra redução do catabolismo dos aminoácidos quando o consumo de nitrogênio é relativamente baixo (YAMASHITA \& ASHIDA, 1969). Contudo, esta hipótese não foi confirmada por Tanaka et al. (1995), que não verificaram influência do teor de proteína no catabolismo dos aminoácidos essenciais.

A Tabela 5 contém o balanço de energia dos suínos alimentados com as rações experimentais. $\mathrm{O}$ aumento da proteína da ração resultou em maior $(\mathrm{P}<0,001)$ energia excretada nas fezes e urina. A energia das fezes aumentou até o teor de $14 \%$ e atingiu o um platô. Assim, os valores energia digestível (ED) das rações experimentais foram diferentes $(\mathrm{P}<0,001)$. As rações com $10 \%$ e $12 \%$ de PB apresentaram valores inferiores (3318 e $3328 \mathrm{kcal}$ ED/kg, respectivamente) em relação às rações com 14\% e 16\% de $\mathrm{PB}$ (3371 e $3361 \mathrm{kcal} \mathrm{ED/kg}$, respectivamente). A energia eliminada na urina aumentou linearmente em resposta ao aumento do teor de proteína bruta da ração, de forma que a energia metabolizável das rações foi semelhante. A relação entre energia metabolizável e energia digestível (EM:ED) foi inversamente proporcional $(\mathrm{P}<0,01)$ ao consumo de nitrogênio. $\mathrm{O}$ efeito dos tratamentos na energia eliminada na urina justifica esses resultados.

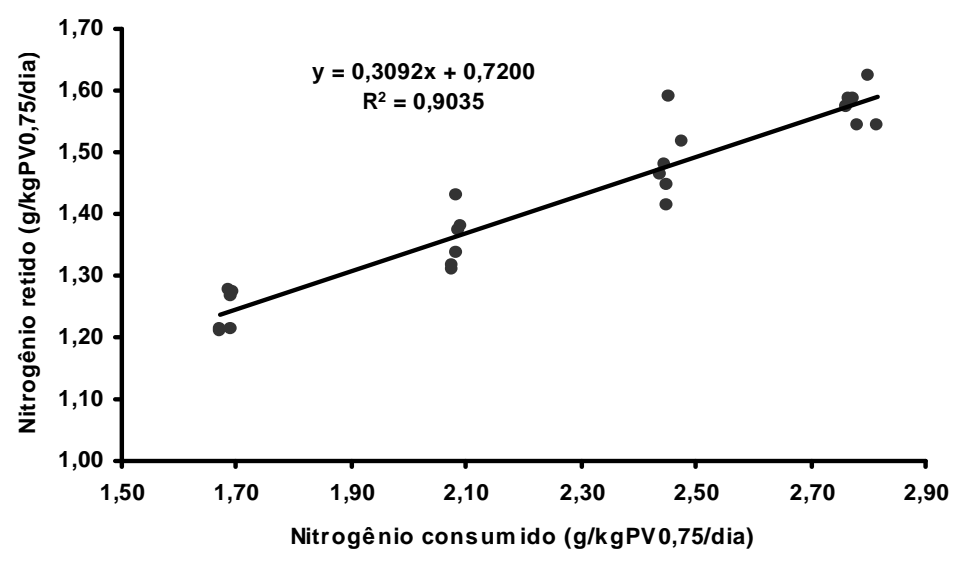

FIGURA 2 - Relação entre nitrogênio ingerido e nitrogênio retido.

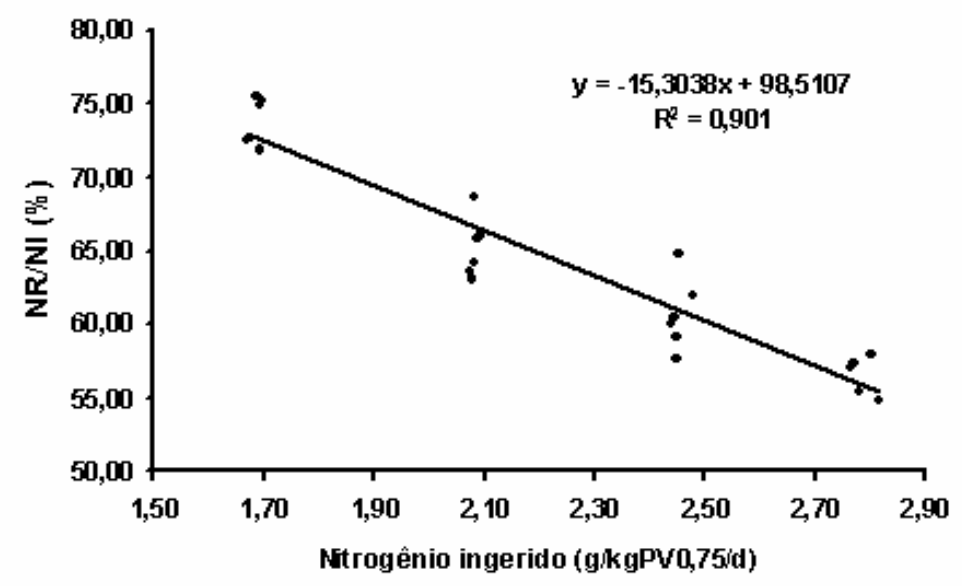

FIGURA 3 - Relação entre nitrogênio ingerido e eficiência de utilização do nitrogênio (NR/NI).

Ciênc. agrotec., Lavras, v. 29, n. 4, p. 866-874, jul./ago., 2005 
TABELA 5 - Efeito do teor de proteína bruta nos valores de energia das rações (na matéria natural).

\begin{tabular}{|c|c|c|c|c|c|}
\hline \multirow{2}{*}{ Variável $^{1}$} & \multicolumn{4}{|c|}{ Teor de PB (\%) } & \multirow{2}{*}{ EPM } \\
\hline & 10 & 12 & 14 & 16 & \\
\hline EB Fezes ${ }^{* *}$ & 34,6 & 43,3 & 49,6 & 48,9 & 1,31 \\
\hline EB Urina* & 7,2 & 8,6 & 9,7 & 11,4 & 0,11 \\
\hline ED & 3318 & 3328 & 3371 & 3361 & 13,45 \\
\hline EM & 3252 & 3228 & 3280 & 3255 & 12,91 \\
\hline $\mathrm{EM}: \mathrm{ED}^{* *}$ & 0,980 & 0,975 & 0,973 & 0,968 & 0,003 \\
\hline
\end{tabular}

${ }^{1}$ Valores expressos em $\mathrm{g} / \mathrm{kgPV}^{0,75} / \mathrm{dia}$.

* Regressão linear significativa $(\mathrm{P}>0,01)$

** Regressão quadrática significativa $(\mathrm{P}>0,01)$.

\section{CONCLUSÕES}

A redução do teor de proteína bruta diminui o nitrogênio excretado pelos suínos e, desta forma, reduz a poluição ambiental. Contudo, essa prática piora a retenção de nitrogênio, mesmo com a suplementação de aminoácidos sintéticos para atender às exigências dos suínos.

Com a redução do teor de proteína da ração, ocorre a diminuição da quantidade de energia eliminada nas fezes e, principalmente, na urina, alterando a relação entre energia metabolizável e digestível da dieta.

\section{REFERÊNCIASBIBLIOGRÁFICAS}

ASSOCIATION OF OFFICIALANALYTICALCHEMIST. Official methods of analysis. 15. ed. Arlington, 1990. 1230 p.

BAKER, D. H. Ideal protein for pigs. In: MINNESOTA NUTRITION CONFERENCE, 1994, Saint Paul. Proceedings... Saint Paul: [s.n.], 1994. p. 235.

BEDFORD, M. R.; SUMMERS, J. D. Influence of the ratio of essential to non essential amino acids on performance and carcass composition of the broiler chick. British Poultry Science, London, v. 26, n. 4, p. 483-491, Oct. 1985.

BIRKE, H.; THORLACIUS-USSING, O.; HESSOV, I. Trophic effect of dietary peptides on mucosa in the rat small bowel. Journal Parenteral and Enteral Nutrition, Silver Spring, v. 14, p. 265, Ago. 1990. Supplement.
CANH, T. T.; AARNINK, A. J. A.; VERSTEGEN, M. W. A.; SCHRAMA, J. W. Influence of dietary factors on the $\mathrm{pH}$ and ammonia emission of slurry from growing-finishing pigs. Journal of Animal Science, Champaign, v. 76, n. 4, p. 1123-1130, Apr. 1998.

FAN, M. Z.; SAUER, W. C.; HARDIN, R. T.; LIEN, K. A. Determination of apparent ileal amino acids digestibility in pigs: effect of dietary amino acid level. Journal of Animal Science, Champaign, v. 72, n. 11, p. 2851-2859, Nov. 1994.

FIGUEROA, J. L.; LEWIS, A. J.; MILLER, P. S.; FISCHER, R. I.; GÓMEZ, R. S.; DIEDRICHSEN, R. M. Nitrogen metabolism and growth performance of gilts fed standard corn-soybean meal diets or low-crude protein, amino acidsupplemented diets. Journal of Animal Science, Champgnion, v. 80, n. 11, p. 2911-2919, 2002.

GILL, J. L.; MAGEE, W. T. Balanced two-period changeover designs for several treatments. Journal of Animal Science, Champaing, v. 42, n. 3, p. 775-777, 1976.

HEGER, J.; MENGESHA, S.; VODEHNAL, D. Effect of essential: total nitrogen ratio on protein utilization in the growing pigs. British Journal of Nutrition, Cambridge, v. 80, p. 537-544, 1998.

KEPARTH, K. B.; SHERRITT, G. W. Performance and nutrient balance in growing swine fed low protein diets supplemented with amino acids and potassium. Journal of animal science, Champignon, v. 68, p. 19992008, 1990. 
KERR, B. J.; EASTER, R. A. Effect of feeding reduced protein, amino acid-supplemented diets nitrogen and energy balance in grower pigs. Journal of Animal Science, Champaign, v. 73, n. 10, p. 3000-3008, Oct. 1995.

LE BELLEGO, L.; MILGEN, J. van; DUBOIS, S.; NOBLET, J. Energy utilization of low-protein diets in growing pigs. Journal of Animal Science, Champaing, v. 79, p. 1259$1271,2001$.

LENIS, P. N.; DIEPEN, H. T. M. van; BIKKER, P.; JONGBLOED, A. W.; MEULEN, J. V. D. Effects of the ratio betwenn essential and nonenssential amino acids in the diet on utilization of nitrogen and amino acids by growing pigs. Journal of Animal Science, Champaign, v. 77, p. 17771787, 1999.

LI, S.; SAUER, W. C.; HARDIN, R. T. Effect of dietary fibre level on amino acid digestibility in young pigs. Canadian Journal of Animal Science, Ottawa, v. 74, n. 2, p. 327-333, Apr. 1994.

NATIONAL RESEARCH COUNCIL. Nutrient requirements of swine. 10. ed. Washington: National Academy of Sciences, 1998.

NOBLET, J.; FORTUNE, H.; SHI, X. S.; DUBOIS, S. Prediction of net energy value of feeds for growing pigs. Journal of Animal Science, Champaing, v. 72, p. 344-354, 1994.

OTTO, E. R.; YOKORAMA, M.; KU, P. K.; AMES, N. K.; TROTTIER, N. L. Nitrogen balance and ileal amino acid digestibility in growing pigs fed diets reduced in protein concentration. Journal Animal Science, Champaign, v. 81, p. 1743-1753, 2003.
PEKAS, J. C. Versatile swine in laboratory apparate for physiologic and metabolic studies. Journal of Animal Science, Champaign, v. 27, n. 5, p. 1303-1306, Feb. 1968.

POULLAIN, M. G.; CEZARD, J. P.; ROGER, L.; MENDY,F. Effects of whey proteins their oligopeptides hydrolisates, and free amino acid mixture on growth and nitrogen retention in feed and starved rats. Journal Parenteral and Enteral Nutrition, Silver Spring, v. 13, n. 2, p. 382-386, Feb. 1989.

SILVA, D. J.; QUEIROZ, A. C. Análises de alimentos: métodos químicos e biológicos. Viçosa: UFV, 2002. 235 p.

TANAKA, H.; SHIBATA, K.; MORI, M.; OGURA, M. Metabolism of essential amino acids in growing rats at grade levels of soybean protein isolate. Journal of Nutritional Science and Vitaminology, Tokyo, v. 41, p. 433-443, 1995.

SOEST, P. J. van; WINE, R. H. Use of detergents in the analysis of fibrous feeds: 4. determination of plant cellwall constituents. Journal Association Agriculture Chemistry, [S.1.], v. 50, p. 50-55, 1967.

WANG, T. C.; FULLER, M. F. The optimum dietary amino acid pattern for growing pigs: I. experiments by amino acid deletion. British Journal of Nutrition, Cambridge, v. 62, n. 1, p. 77-89, July 1989.

YAMASHITA, K.; ASHIDA, K. Lysine metabolism in rats fed lysine-free diet. Journal of nutrition, v. 98, n. 3, p. 267 $273,1969$.

ZALOGA, G. P. Physiologic effects of peptide-based enteral formulas. Nutrition Clinical Practical, [S.1.], v. 5, n. 6, p. 231-237, Dec. 1990. 